\title{
Dual perforator flap for reconstruction of large sacral defect due to electrical blanket
}

Jinkyung Song, M.D., SY Lim, M.D., Department of Plastic and Reconstructive Surgery, Hanil General Hospital, Seoul, Korea

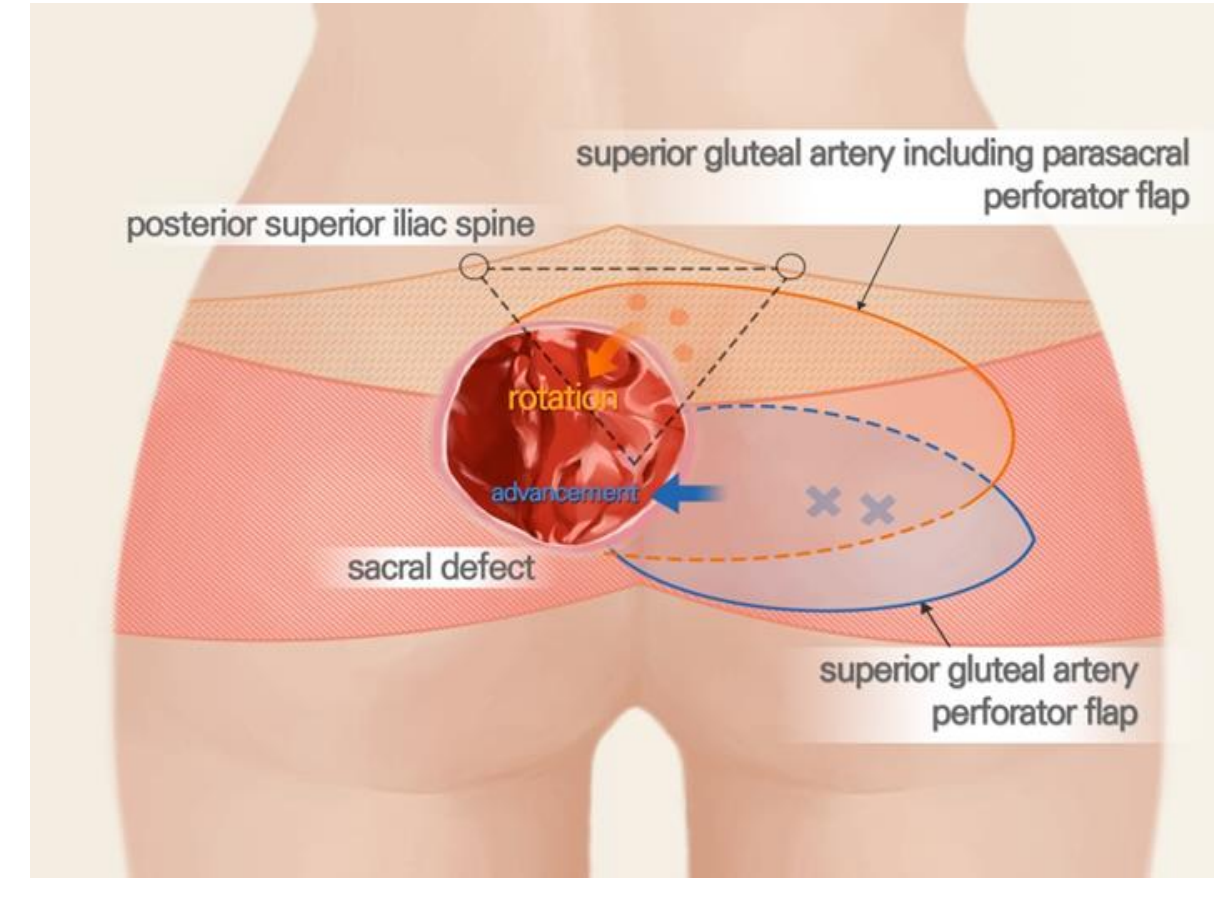

Design of superior gluteal artery super-flap with parasacral perforator.

parasacral perforator angiosome(dotted line) superior gluteal artery perforator angiosome(full line)

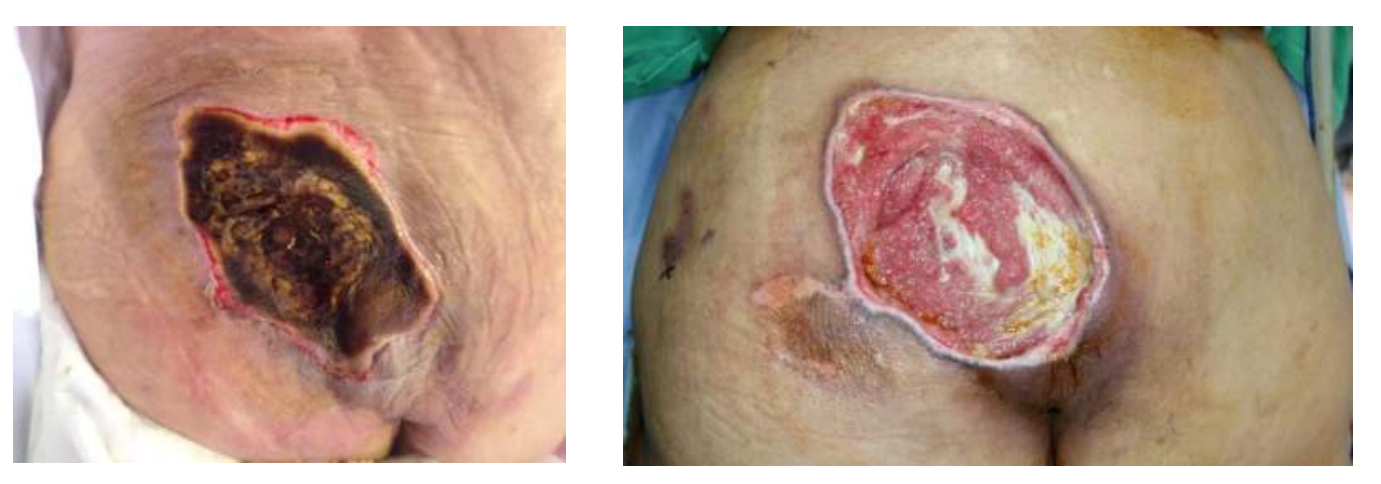

Preoperative photograph


Intraoperative photograph

(Pedicle of superior gluteal artery including perforator and parasacral perforator)

\section{PURPOSE}

An electrical blanket was commonly used in Korea especially in winter season. Contact burn due to electrical blanket was increased in Korea and management of large soft tissue defects in the sacrum has been progressive developed. Management of large soft tissue defects in the sacrum has advanced. The superior gluteal artery perforator flap technique has been increasingly used following its introduction nearly 25 years ago.

We report using the superior gluteal artery perforator flap with additional parasacral perforator supported by different angiosomes to cover large sacral defects due to 4th degree contact burn.

\section{METHODS}

A 79-year-old female with medical history of hypertension was referred for the treatment of $4^{\text {th }}$ degree burns on the sacral area, caused by an electric blanket. After debridement, the sacral wound size was $11 \times 10 \mathrm{~cm}^{2}$. We subsequently planned the superior gluteal artery perforator super-flap with additional parasacral perforator because of the large defect size .

The flap was designed to include the superior gluteal perforator artery with the parasacral perforator artery To obtain sufficient perforator length, the superior gluteal artery pedicle needed to be dissected within the muscle; parasacral perforator dissection was accomplished by meticulous subfascial dissection. After finishing the perforator dissection, the flap was transferred cautiously, taking care not to kink or stretch the dissected perforator.

\section{RESULTS}

Dual perforator flap - Superior gluteal artery and parasacral perforator artery - was well covered the large sacral defect. Postoperative seroma was developed but resolved by conservative treatment.
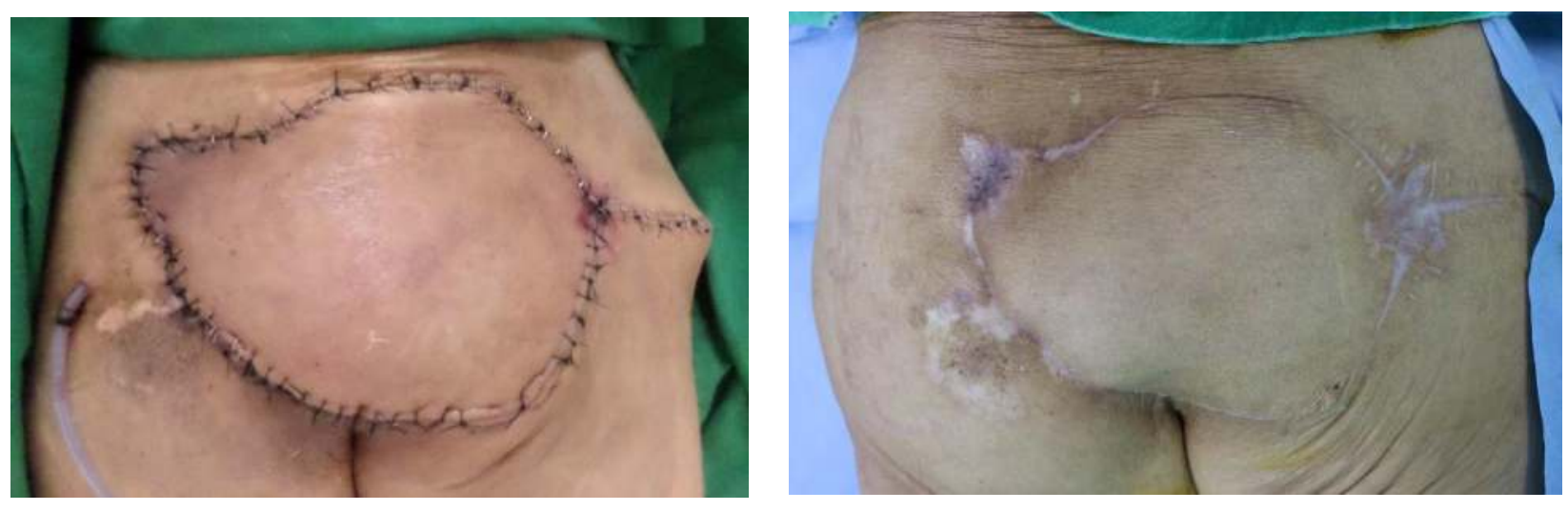

Postoperative photograph

(Immediate and 6 months after operation)

\section{CONCLUSION}

The superior gluteal artery perforator super-flap including parasacral perforator with consideration of angiosome territories can be a good option in covering large sacral defect unable to be covered with unilateral superior gluteal artery perforator flap. This procedure reduces the operation time and prevents unpredictable flap failure. Even though the parasacral perforator is included, versatility of the large superior gluteal artery perforator flap is preserved due to sufficient perforator length gained after adequate dissection.

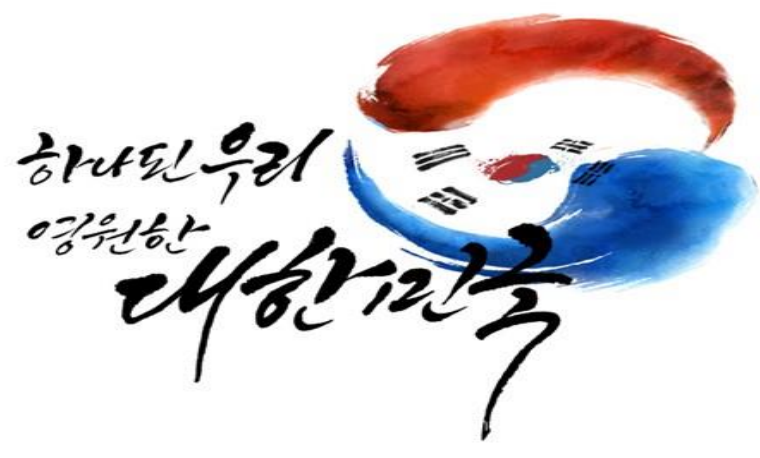

